\title{
Fluxos de óxido nitroso em sistema de integração lavoura-pecuária-floresta
}

\author{
Anna Karolyne da Silva Nogueira(1), Renato de Aragão Ribeiro Rodrigues ${ }^{(2)}$, \\ Jacqueline Jesus Nogueira da Silva(1), Andressa Alves Botin ${ }^{(1)}$, Júlia Graziela da Silveira(1), \\ Mircéia Angele Mombach ${ }^{(3)}$, Natassia Magalhães Armacolo(1) e Sara de Oliveira Romeiro( ${ }^{(3)}$
}

\begin{abstract}
(1)Universidade Federal de Mato Grosso, Campus Universitário de Sinop, CEP 78557-267 Sinop, MT, Brasil. E-mail: anna_lyne_nogueira@hotmail.com, jacqueufmt@gmail.com, andressa.botin@gmail.com, juliagrazielasilveira@gmail.com, nah_armacolo@hotmail.com ${ }^{(2)}$ Embrapa Solos, Rua Jardim Botânico, oㅜ 1.024, Jardim Botânico, CEP 22460-000 Rio de Janeiro, RJ, Brasil. E-mail: renato.rodrigues@embrapa.br ${ }^{(3)}$ Embrapa Agrossilvipastoril, Caixa Postal 343, Zona Rural, CEP 78550-970 Sinop, MT, Brasil. E-mail: mirceia@zootecnista.com.br, sara-romeiro@live.com
\end{abstract}

Resumo - O objetivo deste trabalho foi avaliar o potencial de mitigação de óxido nitroso $\left(\mathrm{N}_{2} \mathrm{O}\right)$ em sistema de integração lavoura-pecuária-floresta (ILPF), em comparação ao monocultivo, e identificar os principais fatores que regulam as emissões deste gás. O experimento foi realizado em Sinop, MT, entre as safras 2012/2013 e 2013/2014, e avaliou os seguintes tratamentos: floresta, lavoura e pastagem, além do ILPF. Durante a realização do experimento, não houve presença de bovinos nas áreas com pastagem. Amostras de óxido nitroso foram coletadas semanalmente, com uso de câmaras estáticas, modelo topo-base. As concentrações do gás foram determinadas por meio de cromatografia gasosa. A precipitação pluvial e a disponibilidade de $\mathrm{N}$ foram os principais fatores reguladores das emissões de $\mathrm{N}_{2} \mathrm{O}$. O sistema de ILPF apresenta potencial promissor para mitigar as emissões de $\mathrm{N}_{2} \mathrm{O}$, com emissão acumulada de $0,367 \mathrm{~kg} \mathrm{ha}^{-1}$ de $\mathrm{N}$, em comparação a de $1,401 \mathrm{~kg} \mathrm{ha}^{-1}$ emitidas pela lavoura; de $0,298 \mathrm{~kg} \mathrm{ha}^{-1}$, pela pastagem; e de $0,165 \mathrm{~kg} \mathrm{ha}^{-1}$, pela floresta.

Termos para indexação: gases de efeito estufa, mudança do clima, sistemas integrados de produção.

\section{Nitrous oxide fluxes in an integrated crop-livestock-forestry system}

\begin{abstract}
The objective of this work was to evaluate the mitigation potential of nitrous oxide in an integrated crop-livestock-forestry system (ICLF), compared with monocultures, and to identify the main factors that regulate the emissions of this gas. The experiment was conducted in the municipality of Sinop, in the state of Mato Grosso, Brazil, between the 2012/2013 and 2013/2014 crop seasons, with the evaluation of the following treatments: forest, crop and pasture, besides ICLF. During the experiment, no cattle were present in the pasture areas. Nitrous oxide samples were collected weekly using top-down static chambers. Gas concentrations were determined with gas chromatography. Rainfall and $\mathrm{N}$ availability were main factors regulating $\mathrm{N}_{2} \mathrm{O}$ emissions. The ICLF system has promising potential to mitigate $\mathrm{N}_{2} \mathrm{O}$ emissions, with $0.367 \mathrm{~kg} \mathrm{ha}^{-1} \mathrm{~N}$ accumulated emission, compared with $1.401 \mathrm{~kg} \mathrm{ha}^{-1}$ from cropland, $0.298 \mathrm{~kg} \mathrm{ha}^{-1}$ from pasture, and $0.165 \mathrm{~kg} \mathrm{ha}^{-1}$ from forest.
\end{abstract}

Index terms: greenhouse gases, climate change, integrated production systems

\section{Introdução}

O sistema de integração-lavoura-pecuária-floresta (ILPF) merece destaque como sistema de produção sustentável (Bonaudo et al., 2014; Franzluebbers et al., 2014), por evitar o desmatamento, respeitar os preceitos de segurança alimentar e da agricultura sustentável, e levar em consideração um cenário de crescente demanda por alimento e energia, frente a uma disponibilidade cada vez menor de recursos naturais (Lemaire et al., 2014; Smith, 2015). O uso desse sistema está em expansão no Brasil, apesar de não haver dados confiáveis sobre a área implantada com esses sistemas no país. Estima-se que seu potencial de adoção está em torno de 68 milhões de hectares, sem que haja necessidade de abertura de novas áreas (Balbino et al., 2011).

Este artigo trata, em especial, das emissões de óxido nitroso $\left(\mathrm{N}_{2} \mathrm{O}\right)$, integrando três componentes: lavoura, pecuária e floresta, em área de transição entre os biomas Cerrado e Amazônia. Esse gás de efeito estufa apresenta potencial de aquecimento global 298 vezes superior ao do dióxido de carbono $\left(\mathrm{CO}_{2}\right)$ (Stocker et al., 2013), e sua emissão ocorre em grande escala 
na agricultura do Brasil, com estimativa de $541 \mathrm{Gg}$ emitidos em 2012 (Estimativas..., 2014).

A ampliação do uso do ILPF e de sistemas agroflorestais (SAFs), em 4 milhões de hectares até 2020, é uma estratégia de intensificação sustentável da produção que faz parte do compromisso voluntário assumido pelo governo brasileiro na 15 . $^{\mathrm{a}}$ Conferência das Partes (COP15, em 2009, na Dinamarca) e serve como base para a elaboração do Plano $\mathrm{ABC}$, que tem por objetivo reduzir as emissões de gases de efeito estufa (GEE) do setor agrícola. Com o aumento das áreas de ILPF e SAFs, visa-se atingir um potencial de mitigação de 18 a 22 milhões $\mathrm{Mg} \mathrm{CO}_{2}$-eq (Plano..., 2012). No entanto, o sistema de ILPF é complexo e pode ser usado em diversos tipos de arranjos, planejados de acordo com características intrínsecas de cada local (Assmann et al., 2014). Além disso, é importante ressaltar que o Brasil tem uma grande extensão territorial, o que implica ampla diversidade de ambientes físicos, que podem influenciar significativamente as emissões de gases de efeito estufa, uma vez que elas estão diretamente ligadas às condições edafoclimáticas, à tecnologia de produção agrícola e ao manejo da cultura utilizada.

Em um estudo realizado no subtrópico brasileiro, em sistema de ILPF com cultivo de aveia-preta (Avena strigosa) e azevém (Lolium multiflorum) como plantas de cobertura de inverno, e soja (Glycine max) ou milho (Zea mays), como culturas de verão, e com eucalipto (Eucalyptus sp.) e grevílea (Grevillea sp.) como componentes florestais, Dieckow et al. (2015) relataram que as emissões acumuladas em 450 dias de avaliação $\left(0,5 \mathrm{~kg} \mathrm{ha}^{-1}\right.$ de $\left.\mathrm{N}_{2} \mathrm{O}-\mathrm{N}\right)$ foram cerca de quatro vezes inferiores à observada no sistema convencional, sem o componente florestal. Os autores atribuíram o resultado às menores médias de temperatura do solo no sistema de ILPF.

No Brasil, o número de pesquisas sobre as emissões de $\mathrm{N}_{2} \mathrm{O}$ em sistemas de ILPF ainda é incipiente, para que se chegue a conclusões sobre a melhor configuração e sobre quais espécies devem ser usadas para diminuir as emissões do gás. Assim, o desenvolvimento de estudos sobre esse tema, em diferentes regiões do país, é fundamental para que esse sistema possa, no futuro, ser usado como alternativa para mitigação das emissões no país.

O objetivo deste trabalho foi avaliar o potencial de mitigação de $\mathrm{N}_{2} \mathrm{O}$ de sistema ILPF, em comparação aos monocultivos, e identificar os principais fatores que regulam as emissões desse gás.

\section{Material e Métodos}

O estudo foi realizado na Fazenda Experimental da Embrapa Agrossilvipastoril, em Sinop, MT, situada em uma zona de transição edafoclimática

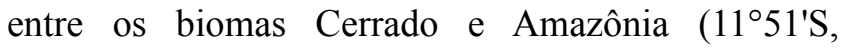
$55^{\circ} 35^{\prime} \mathrm{W}$ e $384 \mathrm{~m}$ de altitude). O clima da região é caracterizado como Aw (tropical com inverno seco), conforme classificação de Köppen-Geiger, com $25^{\circ} \mathrm{C}$ de média anual de temperatura, e $2.550 \mathrm{~mm}$ de média anual de precipitação (Inmet, 2016). O solo foi classificado como Latossolo Vermelho-Amarelo de textura argilosa, com relevo plano e as seguintes características: $\mathrm{pH} \mathrm{H}_{2} \mathrm{O}, 5,7$; matéria orgânica, $3,6 \mathrm{~g} \mathrm{~kg}^{-1}$; areia, $322 \mathrm{~g} \mathrm{~kg}^{-1}$; silte, $118 \mathrm{~g} \mathrm{~kg}^{-1}$; e argila, $560 \mathrm{~g} \mathrm{~kg}^{-1}$.

Parte da área de estudo havia sido desmatada em 1984, para a produção de mandioca (Manihot esculenta Crantz) (Araujo et al., 2009). No início da década de 1990, foi feito o cultivo de arroz (Oryza sativa), seguido por soja (Glycine Max L.). Entre 2002 e 2007, foram cultivados soja e milho (Zea mays), em sistema convencional de preparo do solo. Nas safras de 2007/2008 e 2008/2009, foram plantados soja e algodão (Gossypium hirsutum L.) em sucessão e, em 2010/2011, a área permaneceu em pousio (Diel et al., 2014). O experimento de ILPF foi implantado na safra 2011/2012 (plantio entre novembro de 2011 e janeiro de 2012).

O experimento foi realizado entre as safras 2012/2013 e 2013/2014, e os tratamentos avaliados foram floresta (F), lavoura (L), pastagem (P) e integração lavourapecuária-floresta (ILPF), e não havia bovinos nas áreas com pastagem (Figura 1).

O tratamento $\mathrm{F}$ foi formado por 1 ha do híbrido Eucalyptus urograndis (clone H13), no arranjo 3,0x3,5 m (952 árvores ha ${ }^{-1}$ ), plantado em outubro de 2011. A área com $\mathrm{P}$ abrangeu 2 ha, com Urochloa brizantha 'Marandu', semeada em janeiro de 2012. A área com L ocupou 1 ha, com soja, no verão, e milho de segunda safra consorciado com pasto U. brizantha 'Marandu'. A soja, cultivar BRSGO 8660 (RR) foi semeada em linhas, à taxa de $25 \mathrm{~kg}$ de sementes ha ${ }^{-1}$, em $18 \mathrm{de}$ outubro de 2013. Nessa ocasião, aplicaram-se 200 $\mathrm{kg} \mathrm{ha}^{-1}$ de $\mathrm{N}-\mathrm{P}_{2} \mathrm{O}_{5}-\mathrm{K}_{2} \mathrm{O}$ 00-20-20. A colheita ocorreu em 11 de fevereiro de 2014 e, em seguida, aplicou-se

Pesq. agropec. bras., Brasília, v.51, n.9, p.1156-1162, set. 2016 DOI: $10.1590 / \mathrm{S} 0100-204 X 2016000900015$ 
N- $\mathrm{P}_{2} \mathrm{O}_{5}-\mathrm{K}_{2} \mathrm{O}$ 04-30-16 e realizou-se o plantio do milho cultivar DKB 390 (Vt Pro 2) à taxa de 13,72 $\mathrm{kg} \mathrm{ha}^{-1}$ de sementes, em conjunto com $U$. brizantha 'Marandu' (6,0 $\mathrm{kg} \mathrm{ha}^{-1}$ de sementes). No dia 28 de março de 2014, fez-se a adubação nitrogenada de cobertura ao milho, com $300 \mathrm{~kg} \mathrm{ha}^{-1}$ de $\mathrm{N}$ ureia. A colheita do milho ocorreu em $1^{\circ}$ de julho do mesmo ano e, em 30 de outubro, a soja foi semeada com $25 \mathrm{~kg} \mathrm{ha}^{-1}$ de sementes, tendose aplicado $200 \mathrm{~kg} \mathrm{ha}^{-1}$ de $\mathrm{N}-\mathrm{P}_{2} \mathrm{O}_{5}-\mathrm{K}_{2} \mathrm{O}$ 00-20-20. O sistema de ILPF, com 2 ha, foi constituído pelo clone $\mathrm{H} 13$ de E. urograndis, no arranjo de 3,0x3,5 m (270 árvores ha-1) em faixas triplas, com $30 \mathrm{~m}$ entre renques, e lavoura entre os renques, conforme descrito no tratamento L.

As coletas de $\mathrm{N}_{2} \mathrm{O}$ ocorreram semanalmente, entre 8 e 10 h, de novembro de 2013 a outubro de 2014 . Logo após o acoplamento do topo na base metálica, coletava-se uma amostra de ar atmosférico (cerca de $20 \mathrm{~cm}^{3}$ ) e mais três coletas de ar de dentro de cada câmara estática (modelo topo-base), a cada $20 \mathrm{~min}$, conforme Nogueira et al. (2015).

Nos tratamentos F, L e P, instalou-se uma câmara no meio da parcela. Já no sistema de ILPF, foram instaladas quatro câmaras: a primeira no meio do renque central do eucalipto, a segunda a $3 \mathrm{~m}$ de distância lateral desta, e a terceira e a quarta respectivamente a 6 e a $15 \mathrm{~m}$ da primeira. Termo-higrômetros foram instalados para aferir a temperatura interna da câmara e a umidade relativa do ar.

As bases das câmaras foram confeccionadas em metal, instaladas no campo um dia antes do início da

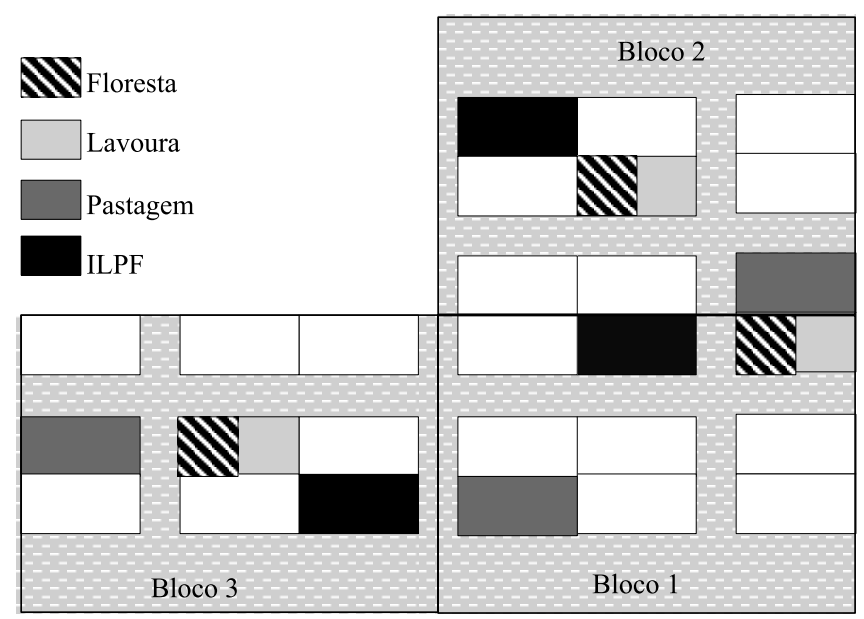

Figura 1. Croqui da área experimental, com a localização dos tratamentos floresta, lavoura, pastagem e integração lavoura-pecuária-floresta (ILPF). primeira coleta e fixadas ao solo à profundidade de 5 $\mathrm{cm}$, tendo permanecido no solo durante todo o período de estudo.

A determinação das concentrações de $\mathrm{N}_{2} \mathrm{O}$ foi feita no laboratório da Embrapa Agrossilvipastoril, em dois cromatógrafos gasosos, modelo GC-2014 (Shimadzu, Kyoto, Japão), com o auxílio de injetor automático. Os cromatógrafos eram equipados com o detector de captura de elétrons (ECD). A temperatura do detector e da coluna cromatográfica foi mantida a $250^{\circ} \mathrm{C}$ e a $75^{\circ} \mathrm{C}$, respectivamente, em sistema isotérmico. As colunas estavam em série Hayesep (1.0 , 4.0 , 1.5 , 1.5, e $0.7 \mathrm{~mol} \mathrm{~L}^{-1}$ ) e o gás de arraste foi o $\mathrm{N}_{2}$.

Para a determinação da curva-padrão, utilizaram-se três soluções gasosas que continham $\mathrm{N}_{2} \mathrm{O}$ (White Martins, Osasco, SP) a 382,8, 808,0 e 2.080, $0 \mathrm{nmol} \mathrm{mol}^{-1}$. O tempo de corrida das amostras foi de $8 \mathrm{~min}$.

$\mathrm{O}$ delineamento experimental em blocos ao acaso foi utilizado com três repetições. Examinaram-se os pressupostos da análise de variância quanto à normalidade, pelo teste de Lilliefors, e quanto à homogeneidade de variâncias, pelos testes de Cochran, Hartley, Bartlett. Verificou-se que os dados não atenderam aos pressupostos da análise de variância, mesmo após a transformação. Assim, os fluxos médios e as emissões acumuladas foram comparados pelo erro padrão da média. Para a determinação da média das emissões sazonais, consideraram-se os meses de novembro a abril como sendo estação chuvosa e de maio a outubro como estação seca.

\section{Resultados e Discussão}

Os fluxos de $\mathrm{N}_{2} \mathrm{O}$ foram predominantemente positivos após eventos de precipitação pluvial; assim, nos meses da estação chuvosa, observaram-se as maiores emissões desse gás em todos os tratamentos (Figura 2).

A precipitação pluvial influencia o percentual de espaços porosos preenchidos por água (EPPA) no solo que, por sua vez, são uma importante fonte reguladora dos processos de nitrificação e desnitrificação (Robertson \& Groffman, 2007). Há níveis de EPPA ideais para que ocorram os dois processos, e isto influencia a quantidade de $\mathrm{N}_{2} \mathrm{O}$ produzido, porém, essa variável não foi mensurada no presente estudo.

Para uma melhor compreensão dos resultados (Figura 2), foi feita uma análise das emissões ocorridas 
sazonalmente, ou seja, nas estações de chuva e de seca, tendo-se os processos que influenciaram os fluxos de $\mathrm{N}_{2} \mathrm{O}$.

A emissão média de $\mathrm{N}_{2} \mathrm{O}$ no tratamento $\mathrm{L}$, na estação chuvosa, foi de $25,5 \pm 2,2 \mu \mathrm{g} \mathrm{m}^{2} \mathrm{~h}^{-1}$ de $\mathrm{N}$, cerca de três vezes superior ao valor encontrado no sistema de ILPF, no mesmo período $\left(7,7 \pm 1,2 \mu \mathrm{g} \mathrm{m}^{2} \mathrm{~h}^{-1}\right)$. Nos tratamentos $\mathrm{F}$ e $\mathrm{P}$, observou-se que durante a estação chuvosa os fluxos não diferiram significativamente. No $F$, o valor médio foi de $6,9 \pm 0,9 \mu \mathrm{g} \mathrm{m}^{2} \mathrm{~h}^{-1} \mathrm{e}$, no tratamento $\mathrm{P}, 6,4 \pm 1,3 \mu \mathrm{g} \mathrm{m}^{2} \mathrm{~h}^{-1}$.

Durante a estação chuvosa, em todos os tratamentos, as emissões de $\mathrm{N}_{2} \mathrm{O}$ foram superiores às da estação seca. A distinção das médias de emissões na estação chuvosa, observadas principalmente entre os tratamentos L e ILPF, possivelmente, aconteceu por diferenças na relação $\mathrm{N}_{2} \mathrm{O} / \mathrm{N}_{2}$. Essa relação é influenciada pela abundância do $\mathrm{NO}_{3}{ }^{-}$no solo, pelo fato de esse mineral ter preferência sobre o $\mathrm{N}_{2} \mathrm{O}$ como aceptor de elétrons, durante a desnitrificação (Wrage et al., 2001).

Assim, alguns pontos devem ser considerados: nota-se que a principal distinção entre os tratamentos
L e ILPF é a presença do componente florestal; cerca de $80 \%$ das emissões de $\mathrm{N}_{2} \mathrm{O}$, no período de estudo, ocorreram quando a cultura de soja estava na área, o que coincidiu com a estação chuvosa; cerca de $10 \%$ das emissões totais ocorreram quando a cultura do milho estava na área, e os meses de maior crescimento da cultura (floração e enchimento de grãos) coincidiram com a estação de seca.

A liberação de exsudatos de $\mathrm{N}$ pela raiz de leguminosas contribui de forma significativa para as emissões de $\mathrm{N}_{2} \mathrm{O}$ (Rochette \& Janzen, 2005). Na cultura da soja, este fato, aliado à maior umidade do solo, pode ter contribuído para que as emissões fossem maiores do que as do milho durante o período em que esta cultura estava no campo. Em um estudo realizado por Xia et al. (2013), as emissões de $\mathrm{N}_{2} \mathrm{O}$ foram maiores na fase de desenvolvimento tardio da planta, quando as raízes e os nódulos da soja estavam entrando em decomposição; além disso, estes autores relatam que os espaços porosos preenchidos por água estavam entre 68 e $80 \%$, o que favoreceu a emissão.

Considerando-se que as emissões no tratamento $\mathrm{L}$ e no ILPF foram superiores às do milho, é necessário

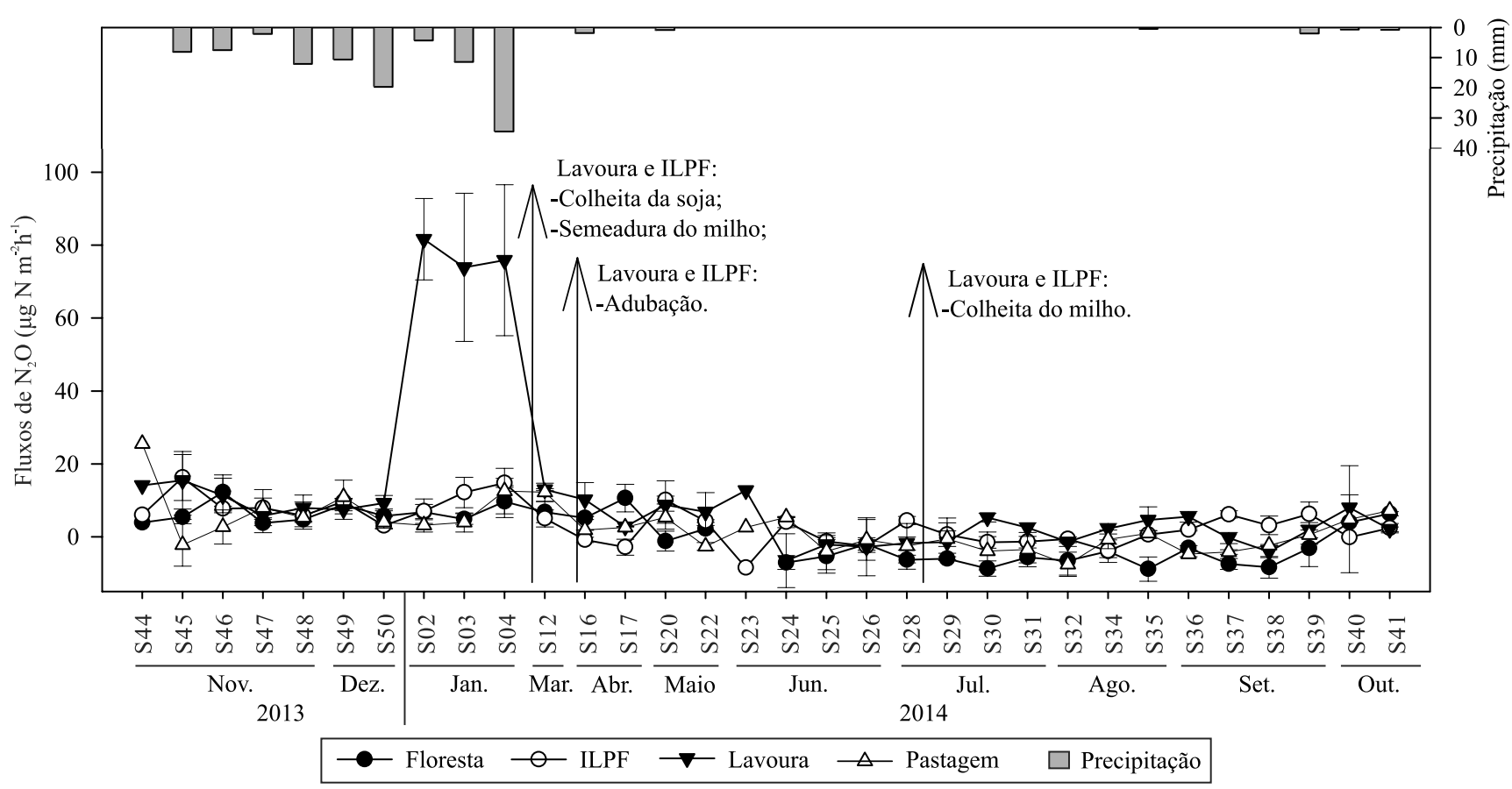

Figura 2. Fluxos de óxido nitroso e precipitação pluvial acumulada, de novembro de 2013 a outubro de 2014. Os valores após as letras $\mathrm{S}$, no eixo $\mathrm{X}$, representam o número da semana, no ano de avaliação para cada coleta. As barras verticais representam o erro padrão da média $(\mathrm{n}=3)$. A precipitação acumulada representa a média de precipitação pluvial dos dois dias anteriores e do dia da coleta. 
entender, ainda, porquê as emissões na lavoura foram maiores do que as do ILPF no mês de janeiro. Uma hipótese do que pode ter ocorrido é fato de a temperatura do solo ter sido maior na área de soja, que estava no tratamento $\mathrm{L}$, e isso pode ter acelerado os processos de mineralização dos resíduos, o que resultaria em maior quantidade de $\mathrm{NO}_{3}{ }^{-}$prontamente disponível para as bactérias realizarem a desnitrificação, enquanto no ILPF, a sombra do componente florestal proporcionou temperaturas mais amenas e uma taxa de decomposição mais lenta. Nota-se que a temperatura do solo já foi associada a menores emissões em sistema de ILPF (Dieckow et al., 2015).

Nos tratamentos F e P, na estação chuvosa, as emissões foram cerca de quatro vezes inferiores às do L e semelhantes às do sistema de ILPF. Os fatores que podem ter contribuído para esse resultado foram: temperaturas do solo mais baixas, proporcionadas pelas árvores (L e ILPF) e pelo tratamento (P); baixa disponibilidade de $\mathrm{NO}_{3}{ }^{-}$, em razão da decomposição mais lenta dos resíduos de eucalipto (F); o alto aporte de $\mathrm{NO}_{3}{ }^{-}$no tratamento $\mathrm{P}$; e a decomposição dos resíduos da soja mais lenta no sistema de ILPF, favorecida pelas temperaturas mais amenas.

Em contrapartida, na estação da seca, as emissões médias no tratamento L e no ILPF foram semelhantes $\left(1,5 \pm 1,1 \mu \mathrm{g} \mathrm{m} \mathrm{m}^{2}\right.$ e $1,5 \pm 0,4 \mu \mathrm{g} \mathrm{m}^{2} \mathrm{~h}^{-1}$ de $\mathrm{N}$, respectivamente). Houve o consumo de $\mathrm{N}_{2} \mathrm{O}$ no tratamento F, de $-4,1 \pm 0,2 \mu \mathrm{g} \mathrm{m}^{2} \mathrm{~h}^{-1}$ e, no $\mathrm{P}$, de $-1,1 \pm 0,3$ $\mu \mathrm{g} \mathrm{m}^{2} \mathrm{~h}^{-1}$. Condições de solo com baixa umidade, ou seja, em condições aeróbicas, favorecem a nitrificação (Wrage et al., 2001).

Observa-se também, que a nitrificação é influenciada pela disponibilidade de amônio, e que esse nutriente é preferencialmente absorvido pelas plantas e em condições específicas de $\mathrm{pH}$ é volatizado na forma de amônia. Infere-se, então que, no período de floração e enchimento de grãos do milho, há uma maior necessidade da cultura de absorver esse nutriente, o que coincidiu com a estação da seca, no tratamento L, período em que essa cultura estava no campo e representou $11 \%$ das emissões totais e, no ILPF, 9\%.

No período de pousio, as emissões representaram $6 \%$ do total para o tratamento L e $8 \%$ no ILPF. Como havia resíduos do milho nas áreas, infere-se que havia uma quantidade baixa de amônio disponível, por isso, as emissões não foram predominantemente negativas. Assim, o valor de emissão baixo dos tratamentos L e ILPF ocorreu, provavelmente, pelo conjunto desses dois fatores: baixa umidade do solo e baixa disponibilidade de amônio.

Nas áreas de $\mathrm{F}$ e $\mathrm{P}$, o consumo de $\mathrm{N}_{2} \mathrm{O}$ foi também favorecido por esses dois fatores. No tratamento $\mathrm{F}$, a baixa taxa de decomposição dos resíduos do eucalipto pode ter favorecido o maior consumo do gás pelas bactérias, enquanto no tratamento $\mathrm{P}$, o aporte de amônio pela cultura pode ter sido o fator que mais contribuiu para o consumo de $\mathrm{N}_{2} \mathrm{O}$.

Assim, nos tratamentos $\mathrm{F}$ e $\mathrm{P}$, a quantidade de $\mathrm{N}$ no solo, na forma prontamente disponível para as bactérias produzirem o $\mathrm{N}_{2} \mathrm{O}$, era inferior à encontrada nos tratamentos de L e P e ILPF, pois, mesmo no período seco, as emissões nesses locais foram positivas.

Os valores encontrados nas emissões acumuladas de $\mathrm{N}_{2} \mathrm{O}$ (Figura 3) trazem um indicativo de que o sistema ILPF apresenta alto potencial de mitigação das emissões desse gás. A interação entre os três componentes proporcionou emissões inferiores às do tratamento $\mathrm{L}$, estatisticamente iguais às do $\mathrm{P}$ (sem a presença do gado), e levemente inferior às do monocultivo de eucalipto. Entretanto, estudos de emissão de gases de efeito estufa e sequestro de carbono no solo, em experimentos de longa duração, ainda são necessários para que se possa compreender melhor a dinâmica das emissões de gases, em sistemas de integração lavourapecuária-floresta.

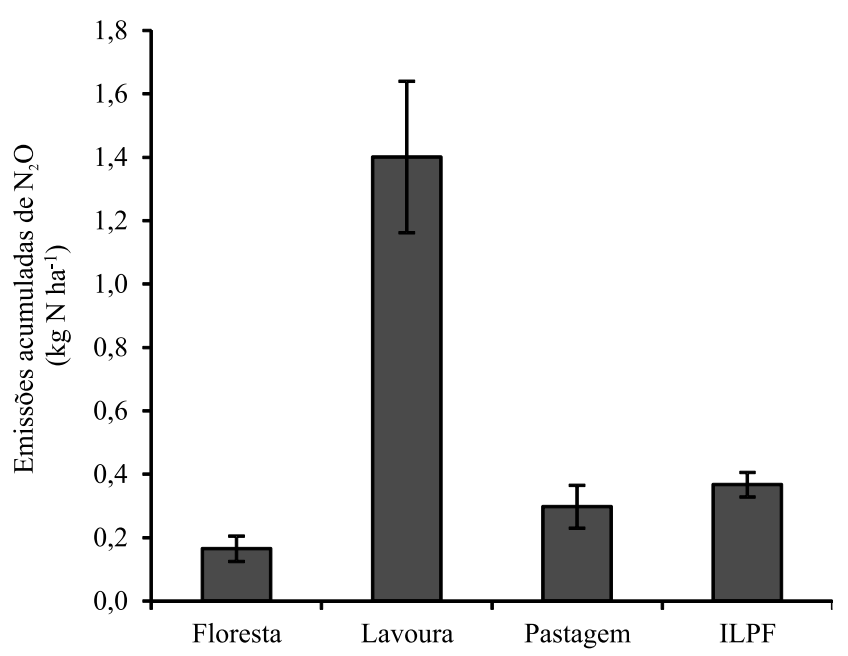

Figura 3. Emissões acumuladas de óxido nitroso no período de novembro de 2013 a outubro de 2014. As barras verticais representam o erro padrão da média $(n=3)$. 


\section{Conclusões}

1. A precipitação pluvial e a disponibilidade de nitrogênio são os principais fatores reguladores das emissões de $\mathrm{N}_{2} \mathrm{O}$ identificados.

2. O sistema de integração lavoura-pecuária-floresta apresenta potencial de mitigação das emissões de $\mathrm{N}_{2} \mathrm{O}$, em comparação ao sistema apenas com lavoura, e pode ser considerado como opção tecnológica para redução de emissões.

\section{Agradecimentos}

Ao Conselho Nacional de Desenvolvimento Científico e Tecnológico (CNPq, projeto no. 472653/2013-0) e ao Ministério do Meio Ambiente, pelo apoio financeiro; à Embrapa, pelo financiamento da pesquisa, por meio dos projetos Saltus e Fluxus; à Coordenação de Aperfeiçoamento de Pessoal de Nível Superior (Capes), à Fundação de Amparo à Pesquisa do Estado de Mato Grosso (Fapemat) e à Rede Clima, pela concessão das bolsas de mestrado e de apoio técnico; à Embrapa Agrossilvipastoril, pela autorização de uso da estrutura do campo experimental e laboratório; e à equipe que auxiliou nas coletas de campo e análises no laboratório.

\section{Referências}

ARAUJO, R. de A.; COSTA, R.B. da; FELFILI, J.M.; GONÇALVEZ, I.K.; SOUZA, R.A.T. de M. e; DORVAL, A. Florística e estrutura de fragmento florestal em área de transição na Amazônia Matogrossense no município de Sinop. Acta Amazonica, v.39, p.865-878, 2009. DOI: 10.1590/S0044-59672009000400015.

ASSMANN, J.M.; ANGHINONI, I.; MARTINS, A.P.; COSTA, S.E.V.G. de A.; CECAGNO, D.; CARLOS, F.S.; CARVALHO, P.C. de F. Soil carbon and nitrogen stocks and fractions in a longterm integrated crop-livestock system under no-tillage in southern Brazil. Agriculture, Ecosystems and Environment, v.190, p.5259, 2014. DOI: 10.1016/j.agee.2014.01.011.

BALBINO, L.C.; BARCELlOS, A. de O.; STONE, L.F. (Ed.). Marco referencial: integração lavoura-pecuária-floresta. Brasília: Embrapa, 2011. 130p.

BONAUDO, T.; BENDAHAN, A.B.; SABATIER, R.; RYSCHAWY, J.; BELLON, S.; LEGER, F.; MAGDA, D.; TICHIT, M. Agroecological principles for the redesign of integrated croplivestock systems. European Journal of Agronomy, v.57, p.4351, 2014. DOI: 10.1016/j.eja.2013.09.010.

DIECKOW, J.; PERGHER, M.; PIVA, J.T.; BAYER, C.; MORAES, A. de; SAKADEVAN, K. Soil nitrous oxide and methane fluxes in integrated crop-livestock systems in subtropics. Soils Newsletter, v.37, 2015. Disponível em: <http://www.iaea.org/inis/collection/
NCLCollectionStore/_Public/46/029/46029483.pdf>. Acesso em: 2 fev. 2016.

DIEL, D.; BEHLING, M.; FARIAS NETO, A.L.; ISERNHAGEN, E.C.C. Distribuição horizontal e vertical de fósforo em sistemas de cultivos exclusivos de soja e de integração lavoura-pecuária-floresta. Pesquisa Agropecuária Brasileira, v.49, p.639-647, 2014. DOI: 10.1590/S0100-204X2014000800008.

ESTIMATIVAS anuais de emissões de gases de efeito estufa no Brasil. 2.ed. Brasília: Ministério da Ciência, Tecnologia e Inovação, 2014. 91p.

FRANZLUEBBERS, A.J.; SAWCHIK, J.; TABOADA, M.A. Agronomic and environmental impacts of pasture-crop rotations in temperate North and South America. Agriculture, Ecosystems and Environment, v.190, p.18-26, 2014. DOI: 10.1016/j. agee.2013.09.017.

GODFRAY, H.C.J.; CRUTE, I.R.; HADDAD, L.; LAWRENCE, D.; MUIR, J.F.; NISBETT, N.; PRETTY, J.; ROBINSON, S.; TOULMIN, C.; WHITELEY, R. The future of the global food system. Philosophical Transactions of the Royal Society B: Biological Sciences, v.365, p.2769-2777, 2010. DOI: 10.1098/ rstb.2010.0180

INMET. INSTITUTO NACIONAL DE METEOROLOGIA. 2016. Disponível em: <http://www.inmet.gov.br/portal/>. Acesso em: 2 fev. 2016.

LEMAIRE, G.; FRANZLUEBBERS, A.; CARVALHO, P.C. de F.; DEDIEU, B. Integrated crop-livestock systems: strategies to achieve synergy between agricultural production and environmental quality. Agriculture, Ecosystems and Environment, v.190, p.4-8, 2014. DOI: 10.1016/j.agee.2013.08.009.

NOGUEIRA, A.K. da S.N.; RODRIGUES, R. de A.R.; CASTRO, B.S.; NOGUEIRA, T.F.; SILVA, J.J.N. da.; BEHLING, M.; MOMBACH, M.; ARMACOLO, N.; SILVEIRA, J.G. Emissões de óxido nitroso e metano do solo em áreas de recuperação de pastagens na Amazônia matogrossense. Química Nova, v.38, p.937-943, 2015. DOI: 10.5935/0100-4042.20150109.

PLANO setorial de mitigação e de adaptação às mudanças climáticas para a consolidação de uma economia de baixa emissão de carbono na agricultura: plano ABC (Agricultura de Baixa Emissão de Carbono). Brasília: Ministério da Agricultura, Pecuária e Abastecimento, 2012. 173 p.

ROBERTSON, G.P.; GROFFMAN, P.M. Nitrogen transformations. PAUL, E.A. (Ed.). Soil microbiology, biochemistry and ecology. $3^{\text {rd }}$ ed. Oxford: Elsevier, 2007. p.341-364. DOI: 10.1016/b978-008-047514-1.50017-2.

ROCHETTE, P.; JANZEN, H.H. Towards a revised coefficient for estimating $\mathrm{N}_{2} \mathrm{O}$ emissions from legumes. Nutrient Cycling in Agroecosystems, v.73, p.171-179, 2005. DOI: 10.1007/s10705005-0357-9.

SMITH, P. Malthus is still wrong: we can feed a world of 9-10 billion, but only by reducing food demand. Proceedings of the Nutrition Society, v.74, p.187-190, 2015. DOI: 10.1017/ S0029665114001517.

STOCKER, T.F.; QIN, D.; PLATTNER, G.-K.; TIGNOR, M.; ALLEN, S.K.; BOSCHUNG, J.; NAUELS, A.; XIA, Y.; BEX, V.; 
MIDGLEY, P.M. (Ed.). Climate change 2013: the physical science basis. Working Group I Contribution to the Fifth Assessment Report of the Intergovernmental Panel on Climate Change. Cambridge: Cambridge University, 2013. 1535p.

WRAGE, N.; VELTHOF, G.L.; BEUSICHEM, M.L. van; OENEMA, O. Role of nitrifier denitrification in the production of nitrous oxide. Soil Biology and
Biochemistry, v.33, p.1723-1732, 2001. DOI: 10.1016/ S0038-0717(01)00096-7.

XIA, Z.; XU, H.; CHEN, G.; DONG, D.; BAI, E.; LUO, L. Soil $\mathrm{N}_{2} \mathrm{O}$ production and the $\delta^{15} \mathrm{~N}-\mathrm{N}_{2} \mathrm{O}$ value: their relationship with nitrifying/denitrifying bacteria and archaea during a growing season of soybean in northeast China. European Journal of Soil Biology, v.58, p.73-80, 2013. DOI: 10.1016/j.ejsobi.2013.05.008.

Recebido em 31 de agosto de 2015 e aprovado em 25 de fevereiro de 2016 